\title{
Deteksi Dini Kanker Payudara Melalui Pemeriksaan Sadanis (Pemeriksaan Payudara Dengan Tenaga Medis) Di Desa Babakan Kecamatan Ciparay Kabupaten Bandung
}

\author{
Tri Ardayani ${ }^{1}$, Liliek Fauziah ${ }^{2}$, Neti Sitorus ${ }^{3}$ \\ Sekolah Tinggi Ilmu Kesehatan Immanuel Bandung \\ Jl. Kopo No.161, Situsaeur, Kec. Bojongloa Kidul, Kota Bandung, Jawa Barat 40232. 1,2,3 \\ Email: triardayani@gmail.com
}

\begin{abstract}
ABSTRAK
Kanker payudara (KPD) masih menjadi masalah kesehatan masyarakat di seluruh dunia, dikarenakan banyaknya kesakitan dan kematian akibat kanker. Di Indonesia di laporkan bahwa kanker payudara mayoritas ditemukan pada kelompok wanita, meskipun angka insidensi kanker payudara ini menduduki peringkat kedua di antara Negara asia Peningkatan angka kejadian kanker payudara terutama di Negara berkembang dikarenakan adanya perubahan gaya hidup diantaranya: rendahnya partisipasi masyarakat dalam olahraga, peningkatan jumlah orang yang mengalami obesitas, dan konsumsi alcohol. Beberapa program untuk mengurangi faktor risiko kanker payudara telah dilakukan diantaranya skrining kanker payudara (SADANIS) di mana pemeriksaan payudara dilakukan oleh petugas medis, dimana SADANIS lebih murah dan mudah bila dibandingkan dengan pemeriksaan Mammography. Tujuan kegiatan pengabdian masyarakat yang dilakukan oleh Sekolah Tinggi Ilmu Kesehatan Immanual bekerjasama dengan Puskesmas Pakutandang Kecamatan Ciparay Kabupaten Bandung untuk meningkatkan pengetahuan kelompok PUS (pasangan usia subuh) dan WUS (wanita usia subut) dan mengetahui lebih dini tanda dan gejala dari kanker payudara serta menurunkan angka kejadian kanker payudara di tahun 2020. Metode pelaksanaan kegiatan tersebut meliputi: Pendidikan kesehatan pada kelompok PUS, WUS, Lansia tentang kanker payudara. Pendidikan kesehatan dan pelatihan pada kelompok Kader tentang pemeriksaan kanker payudara. Pemeriksaan deteksi dini kanker payudara (SADANIS) Stikes Immanuel dan Tenaga Kesehatan Puskesmas Pakutandang (Dokter dan Bidan). Hasil dari kegiatan pengabdian masyarakat ini antara lain: meningkatnya pengetahuan pada kelompok PUS, WUS, Lansia tentang kanker payudara, meningkatnya pengetahuan pada kelompok Kader tentang pemeriksaan kanker payudara. Meningkatnya pengetahuan dan keterampilan pada kelompok kader melakukan pemeriksaan sadanis.
\end{abstract}

Kata Kunci: Kanker Payudara, Sadanis

\begin{abstract}
Breast cancer is still a public health problem throughout the world due to the great amount of pain and death from cancer. In Indonesia, it was reported that the majority of breast cancers were found in the group of women, although the incidence of breast cancer was ranked second among Asian countries Increased incidence of breast cancer, especially in developing countries due to lifestyle changes including low community participation in sports, an increasing number people who are obese, and alcohol consumption. Several programs to reduce risk factors for breast cancer have been carried out including breast cancer screening ( where breast examinations are carried out by medical staff, where BREAST EXAMINATION WITH MEDICAL is cheaper and easier when compared to Mammography examinations. The aim of community service activities conducted by the Immanuel College of Health in collaboration with Public Health centerPakutandang, Ciparay Subdistrict, Bandung Regency is to increase the knowledge of EFA groups (early age couples) and women of childbearing age and find out early signs and symptoms of breast cancer and reduce the number the incidence of breast cancer in 2020. Methods of implementing these activities include Health education in the EFA, WUS, Elderly groups about breast cancer. Health education and training for cadre groups on breast cancer screening. Examination of early detection of breast cancer (BREAST EXAMINATION WITH MEDICAL) Health
\end{abstract}


science Immanuel and Public health centerPakutandang Health (Doctors and Midwives). The results of these community service activities include increased knowledge in the EFA group, WUS, elderly about breast cancer, increased knowledge in the cadre group about breast cancer screening. Increased knowledge and skills in the cadre group conducting conscious checks.

Keywords: Breast Cancers, Sadanis

\section{PENDAHULUAN}

Kanker payudara (KPD) masih menjadi masalah kesehatan masyarakat di seluruh dunia, dikarenakan banyaknya kesakitan dan kematian akibat kanker. Berdasarkan data Globocan terdapat 2.1 juta kasus baru penderita kanker (Bray, 2018), selain kanker payudara di laporkan menjadi penyebab kematian utama pada kelompok wanita baik di Negara maju maupun berkembang (Ghanchch, 2016). Di Indonesia di laporkan bahwa kanker payudara mayoritas ditemukan pada kelompok wanita, meskipun angka insidensi kanker payudara ini menduduki peringkat kedua di antara Negara Asia (Youlden, 2014).

Peningkatan angka kejadian kanker payudara terutama di Negara berkembang dikarenakan adanya perubahan gaya hidup diantaranya: rendahnya partisipasi masyarakat dalam olahraga, peningkatan jumlah orang yang mengalami obesitas, dan konsumsi alcohol (Bray, 2018). Angka kematian penderita kanker payudara di Negara maju lebih rendah dibandingkan dengan Negara berkembang. Hal ini dikarenakan penemuan penderita kanker payudara lebih awal member peluang besar kepada pasien untuk mendapatkan pengobatan lebih dini (Oeffinger, 2015)

Beberapa program untuk mengurangi faktor risiko kanker payudar telah dilakukan antaranya Mammography adalah satu-satunya skrining yang direkomendasikan oleh Word Health Organization (WHO), namun penemuan penderita secara missal dengan menggunakan metode skrining ini sangat sulit dilakukan terutama di Negara berkembang termasuk di Indonesia. Biaya yang relative tinggi untuk melakukan Mammography diidentifikasi sebagai faktor utama tidak dilakukanya skrining kanker payudara secara masal. Pemberdayaan masyarakat dan pelayanan kesehatan melalui kerjasama lintas pendidikan dan petugas kesehatan dapat dilakukan melakukan skrining kanker payudara (SADANIS) di mana pemeriksaan payudara dilakukan oleh petugas medis, dimana SADANIS lebih murah dan mudah bila dibandingkan dengan pemeriksaan Mammography (Elsaghir, 2011). Khusus di Indonesia belum adanya program skrining rutin dari pemerintah dikarenakan lemahnya tenaga kesehatan dan infrastruktur pelayanan kesehatan juga memicu tingginya tingkat kesakitan dan kematian kanker payudara, disamping kesadaran masyarakat mengenali tanda dan gejala awal kanker payudara masih rendah (Hossain, 2014)

Tujuan kegiatan pengabdian masyarakat yang dilakukan oleh Sekolah Tinggi Ilmu Kesehatan Immanual bekerjasama dengan Puskesmas Pakutandang Kecamatan Ciparay Kabupaten Bandung untuk meningkatkan pengetahuan kelompok PUS (pasangan usia subuh) dan WUS (wanita usia subut) dan mengetahui lebih dini tanda dan gejala dari kanker payudara serta menurunkan angka kejadian kanker payudara di tahun 2020.

Masalah yang ditemukan di Desa Babakan Kecamatan Ciparay Kabupaten Bandung yaitu masih kurangnya pengetahuan PUS, WUS dan lansia tentang tanda dan gejala dari 
kanker payudara, belum pernah ada pemeriksaan deteksi dini kanker payudara. Target luaran di harapkan yaitu:

1. Meningkatkan pendidikan kesehatan pada kelompok PUS, WUS dan lansia tentang tanda dan gejala dari kanker payudara

2. Meningkatkan pendidikan kesehatan pada kelompok PUS, WUS dan lansia tentang pemeriksaan deteksi dini kanker payudara

3. Membantu program pemerintah dalam mendeteksi dini kanker payudara pada wanita

4. Mendeteksi dini kejadian kanker payudara pada PUS, WUS dan lansia sehingga memberikan pengobatan lebih awal untuk pencegahan komplikasi lebih lanjut

5. Menjalin kerjasama lintas pendidikan dengan tenaga kesehatan dalam meningkatkan derajat kesehatan masyarakat

\section{METODE}

Metode yang digunakan untuk mengwujudkan tujuan tersebut adalah dengan kaji tindak partisipasif masyarakat (PUS, WUS, Lansia dan Kader) antara tim kegiatan pengabdian masyarakat (STIKES Immanuel Bandung) dengann mitra (tenaga kesehatan Puskesmas Pakutandang). Metode pelaksanaan kegiatan tersebut meliputi:

1. Pendidikan kesehatan pada kelompok PUS, WUS, Lansia tentang kanker payudara

Pendidikan kesehatan pada kelompok PUS, WUS dan lansia di lakukan dalam 2 tahap, hal ini dilakukan karena ada sebagian PUS, WUS dan lansia yang tidak bisa meninggalkan pekerjaan, belum mengetahui informasi adanya kegiatan tersebut, masih adanya perasaan ragu/malu untuk melakukan pemeriksaan tersebut sehingga dilakukan pada hari Rabu, 16 Oktober 2019 s.d Kamis, 17 Oktober 2019 selama dua hari.

Materi yang diberikan meliputi: pengertian kanker payudara, penyebab, tanda dan gejala, pemeriksaan, pengobatan dan pencegahan kanker payudara pada wanita. Narasumber dalam pendidikan kesehatan ini dari dosen sekolah tinggi ilmu kesehatan Immanuel dibantu oleh mahasiswa.

2. Pendidikan kesehatan dan pelatihan pada kelompok Kader tentang pemeriksaan kanker payudara

Pendidikan kesehatan dan pelatihan pada kelompok kader di lakukan 1 tahap pada hari Rabu, 16 Oktober 2019 selama satu hari, dimana para kader di berikan pendidikan kesehatan tentang kanker payudara dan bagaimana cara pemeriksaan deteksi dini kanker payudara secara sendiri jika tidak ada petugas kesehatan tujuanya dapat mengajarkan juga kepada masyarakat dalam pencegahan kanker payudara.

Materi yang diberikan meliputi : pengertian kanker payudara, penyebab, tanda dan gejala, pemeriksaan, pengobatan dan pencegahan kanker payudara pada wanita. Narasumber dalam pendidikan kesehatan ini dari dosen sekolah tinggi ilmu kesehatan Immanuel dibantu oleh mahasiswa.

3. Pemeriksaan deteksi dini kanker payudara (SADANIS) Stikes Immanuel dan Tenaga Kesehatan Puskesmas Pakutandang (Dokter dan Bidan)

Pemeriksaan ini di lakukan pada kelompok WUS, PUS, lansia dan Kader, pemeriksaan deteksi dini kanker payudara dilakukan dalam 2 tahap hal ini dilakukan 
karena ada sebagian PUS, WUS, lansia dan kader yang tidak bisa meninggalkan pekerjaan, belum mengetahui informasi adanya kegiatan tersebut, masih adanya perasaan ragu/malu untuk melakukan pemeriksaan tersebut sehingga dilakukan pada hari Rabu, 16 Oktober 2019 s.d Kamis, 17 Oktober 2019 selama dua hari. Pemeriksaan meliputi pemeriksaan pada payudara kiri dan kanan. Narasumber dalam pemeriksaan ini adalah dosen kebidanan dari Stikes Immanuel, Dokter dan Bidan dari Puskesmas Pakutandang.

\section{HASIL, PEMBAHASAN, DAN DAMPAK}

Hasil dan pembahasan dari kegiatan pengabdian masyarakat ini antara lain:

1. Pendidikan kesehatan pada kelompok PUS, WUS, Lansia tentang kanker payudara

Tujuan kegiatan ini adalah dapat meningkatkan pengetahuan PUS, WUS dan lansia tentang kanker dan pencegahanya antara lain pengertian, penyebab, tanda dan gejala, pemeriksaan, pengobatan dan pencegahan kanker payudara. Target luaran yang dicapai : PUS, WUS, lansia yang mengikuti kegiatan ini sebanyak 30 orang, peserta dapat mempresentasikan kembali materi yang telah dijelaskan, peserta dapat menjawab pertanyaan yang diberikan oleh tim pengabdian masyarakat.

2. Pendidikan kesehatan dan pelatihan pada kelompok Kader tentang pemeriksaan kanker payudara

Tujuan kegiatan ini adalah dapat meningkatkan pengetahuan kader tentang kanker, pencegahan dan pemeriksaanya antara lain pengertian, penyebab, tanda dan gejala, pemeriksaan, pengobatan dan pencegahan kanker payudara. Target luaran yang dicapai : kader yang mengikuti kegiatan ini sebanyak 20 orang, peserta dapat mempresentasikan kembali materi yang telah dijelaskan, peserta dapat menjawab pertanyaan yang diberikan oleh tim pengabdian masyarakat dan mampu mempraktekkan kembali cara pemeriksaan payudara kanan dan kiri.

3. Pemeriksaan SADANIS pada kelompok WUS, PUS, lansia dan Kader pada payudara

Tujuan kegiatan ini adalah dapat membantu program pemerintah dalam mendeteksi dini kanker payudara pada wanita, mendeteksi dini kejadian kanker payudara pada PUS, WUS dan lansia sehingga memberikan pengobatan lebih awal untuk pencegahan komplikasi lebih lanjut, menjalin kerjasama lintas pendidikan dengan tenaga kesehatan dalam meningkatkan derajat kesehatan masyarakat. Target luaran yang dicapai : PUS, WUS, lansia dan Kader yang mengikuti kegiatan ini sebanyak 50 orang, peserta dapat mempresentasikan kembali materi yang telah dijelaskan, peserta dapat menjawab pertanyaan yang diberikan oleh tim pengabdian masyarakat dan kader mampu mempraktekkan kembali cara pemeriksaan payudara kanan dan kiri. 
Rapat Koordinasi STIKES Immanuel dengan Dokter dan Bidan Puskesmas Pakutandang dalam kegiatan pemeriksaan SADANIS

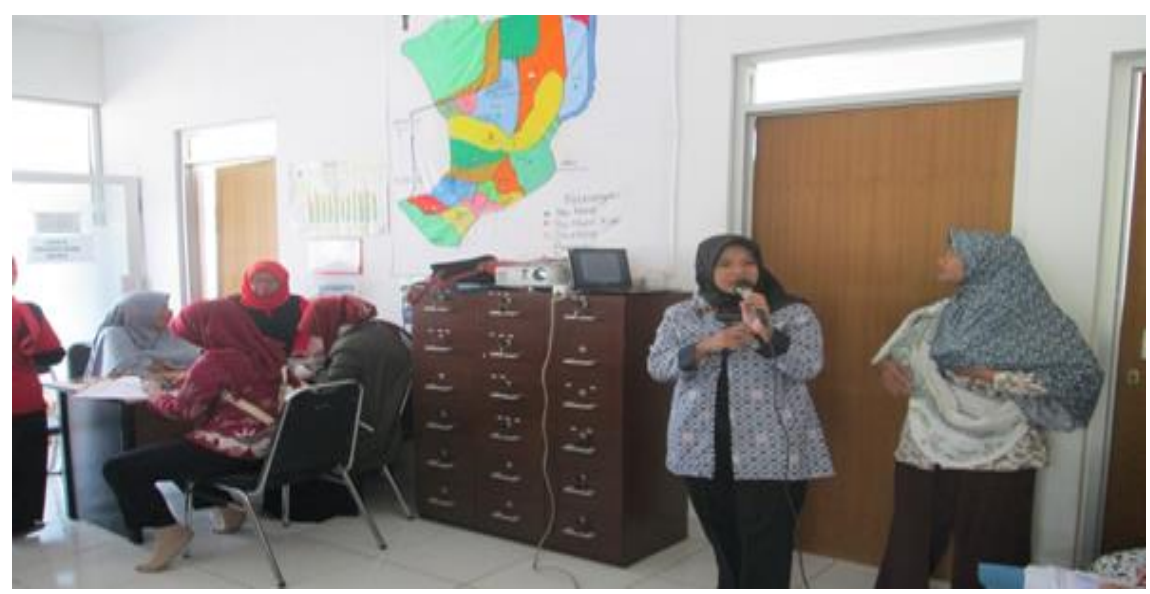

Kegiatan memberikan penyuluhan kepada kelompok PUS, WUS, Lansia tentang kanker payudara

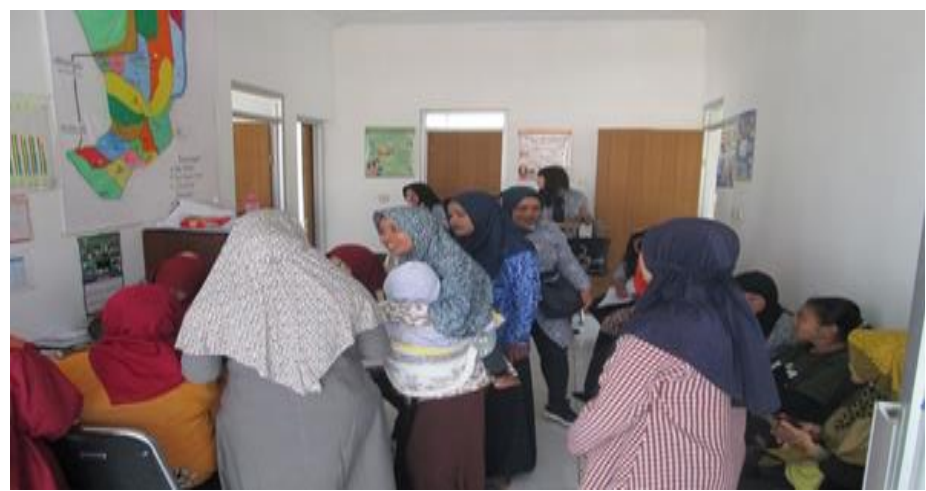

Kegiatan pemeriksaan sadanis di Kecamatan Ciparay di Puskemas Pembantu

\section{SIMPULAN}


Meningkatnya pengetahuan kelompok PUS, WUS dan lansia tentang kanker payudara serta pencegahanya, meningkatnya pengetahuan dan keterampilan kelompok kader tentang kanker payudara dan pemeriksaan pada payudara, di harapkan kader dapat melakukan pemeriksaan payudara, wanita beresiko kanker payudara mendapatkan tindakan lebih lanjut dari tenaga kesehatan Puskesmas Pakutandang (dokter dan bidan) untuk pengobatan.Mitra diharapkan dapat melakukan pemeriksaan kembali din tahun mendatang. Tim pengabdian masyarakat dapat melakukan pemantauan secara periodik pada kelompok PUS, WUS, lansia dan kader di kegiatan pengabdian masyarakat mendatang.

\section{DAFTAR PUSTAKA}

Bray F, Ferlay J, Soejomataram I, Siegel RT, Torre LA, Jemal A. Global Cancer Statistics 2018: GLOBOCAN estimates of incidence and Mortality Worldwide for 36 Cancer in 185 Countries. Ca cancer J Clin. 2020 Pebruari.

Ghonchch M, Pounamdar Z, Salehiniya H. Incidence and Mortalily and Epidemiology of Breas Cancer in the World. Asian Pac J Cancer Prev, 2016

Youlden DR, Cramb SM, Yip CH, Baade PD. Incidence and Mortality of Female Breast Cancer in the Asia-Pacipic Region. Cancer Bio Med. 2014

Oeffinger KC, Fotham ETH, Etzioni R, Herzig A, Michaelson JS, Shih Y-CT, et al. Breas Cancer Screening for Woman at Average Risk: 2015 Guideline Update From the American Cancer Society. JAMA, 2015

El Saghir NS, Adebamowo CA, Anderson BO, Carlson RW, Bird PA, Corbex M, et al. Breas Cancer Management in Low Resouerce Countries (LRScs) : Consensus Statement from the Breas Health Global Initiative. The Breas 2011.

Hossain MS, Ferdous S, Karim-Kos HE, Breas Cancer in South Asia: A Bangladeshi Perspective. Cancer Epidemiol. 2014 